\title{
SYNTHESIS OF DRIVING CYCLES IN ACCORDANCE WITH THE CRITERION OF SIMILARITY OF FREQUENCY CHARACTERISTICS
}

\section{SYNTEZA TESTÓW JEZDNYCH ZGODNIE Z KRYTERIAMI PODOBIEŃSTWA CHARAKTERYSTYK CZĘSTOTLIWOŚCIOWYCH*}

\begin{abstract}
This paper presents an original method of synthesizing driving cycles treated as sets of realizations of a stochastic process of car velocity. The proposed method is based on the criterion of similarity of amplitude-frequency characteristics of test and on-road cycles. Because a driving cycle is treated here as a set of realizations of a random process, the method allows not only to determine the values of zero-dimensional characteristics defining the properties of a car, but also to perform probabilistic evaluation of these properties. In the present study, example realizations of the stochastic velocity process were obtained and analyzed using a test based on the amplitude-frequency characteristics of the Federal Test Procedure cycle-FTP-75.
\end{abstract}

Keywords: cars, driving cycles, frequency characteristics.

\begin{abstract}
W pracy przedstawiono autorska metodę syntezy testów jezdnych, traktowanych jako zbiór realizacji procesu stochastycznego prędkości samochodu, z zastosowaniem kryterium podobieństwa charakterystyki amplitudowo-częstotliwościowej $w$ warunkach badań i rzeczywistego użytkowania pojazdu. Dzięki potraktowaniu testu jako zbioru realizacji procesu przypadkowego jest możliwe w proponowanej metodzie nie tylko wyznaczanie wartości ocenianych zerowymiarowych charakterystyk, określających właściwości użytkowe samochodów, ale i jest możliwa również ocena probabilistycznych właściwości tych wielkości. W pracy wyznaczono i przebadano przyktadowe realizacje procesu stochastycznego prędkości w teście na podstawie charakterystyki amplitudowo-częstotliwościowej testu FTP-75 (Federal Test Procedure-federalna procedura badawcza).
\end{abstract}

Stowa kluczowe: samochody, testy jezdne, charakterystyki częstotliwościowe.

\section{Introduction}

The aim of this study was to present a new method of generating driving cycles understood as realizations of a stochastic process modelling the actual conditions of usage of motor vehicles. The originality of the proposed method lies not only in the fact that it treats driving cycles as realizations of a stochastic process, but also in that it adopts similarity of frequency-domain characteristics between on-road driving and test driving as a criterion for the synthesis of driving cycles. Driving cycle tests are used to assess the performance of vehicles. The main performance parameters evaluated using driving cycles include pollutant emissions, fuel consumption and power consumption. While tests conducted using classical cycles allow to assess the performance of vehicles in the causal conditions of their movement, the use of driving cycles which are realizations of a stochastic velocity process also makes possible assessment of the probabilistic properties of the parameters tested.

Driving cycles can be developed using the following assumptions [3, 4, 9, 17]:

- a driving cycle has a predefined process of velocity relative to maximum velocity,

- a driving cycle faithfully simulates a velocity process in the time domain

- other methods, e.g. a driving cycle meets the criterion of similarity of parameters of the velocity process in different domains, e.g. the time domain, the domain of an independent variable of the integral transform of the time curve, or the process value domain.

The criterion adopted for the development of driving cycles is the similarity of zero-dimensional characteristics of cycles and velocity processes observed during real-world vehicle operation and during tests $[3,4,9,17]$.

The parameters of the velocity process to be used in constructing a driving cycles can be determined for the following domains [4]:

- time domain,

- domain of an independent variable of the integral transform of the time curve, most commonly frequency,

- process value domain.

The most commonly used zero-dimensional parameter in the time domain is average velocity $[3,4,9,17]$. Other parameters in this domain include root mean square value, variance, standard deviation, median, and extreme values (min., max.) [2, 3]. Some driving cycles are based on other zero-dimensional parameters, such as mean absolute value of the velocity-acceleration product or the mean velocitypositive acceleration product $[3,4,9,17]$.

The parameters determined in the frequency domain are most commonly amplitude and phase parameters, and their values for specific frequencies or their average values for frequency ranges constitute representative data points $[4,17]$.

The basic parameter in the value domain is the probability density function and its zero-dimensional parameters, e.g. the most probable value, or parameters of standard probability density functions approximating - in accordance with the criterion adopted - the investigated probability density function $[4,8]$.

Construction of cycles in accordance with the principle of faithful simulation of a velocity process in the time domain may involve $[2,3$, $7,9,12,13,17,22,23]$ :

(*) Tekst artykułu w polskiej wersji językowej dostępny w elektronicznym wydaniu kwartalnika na stronie www.ein.org.pl 
- selection of portions of the velocity-time process representative of the velocity process tested,

- synthesis of the selected portions of the velocity-time process representative of the velocity process tested.

Most cycles currently used for testing passenger cars and lightduty trucks have been developed in accordance with the principle of exact simulation of driving velocity in the time domain $[2,7,12,13$, $17,22,23]$, in particular driving cycles created in the United States of America, for example, the Federal Test Procedure - FTP-75 [23]. Heavy-duty vehicles, such as buses and trucks, are also tested using cycles faithfully simulating the velocity process in the time domain [12]. Cycles with predefined processes of velocity relative to maximum velocity (legislative cycles) include the New European Driving Cycle - NEDC, which consists of the Urban Driving Cycle - UDC and the Extra Urban Driving Cycle - EUDC, and the Japanese driving cycle - Japan 10-15 Mode [23].

This article presents a methodology for generating cycles treated as realizations of a stochastic process which models real-world driving conditions. The method is based on the criterion of similarity of frequency domain parameters in on-road and test driving conditions. The FTP-75 cycle (Figure 1) was adopted as a reference velocity process, whose amplitude-frequency characteristics were used as criteria for comparison of similarity between cycles.

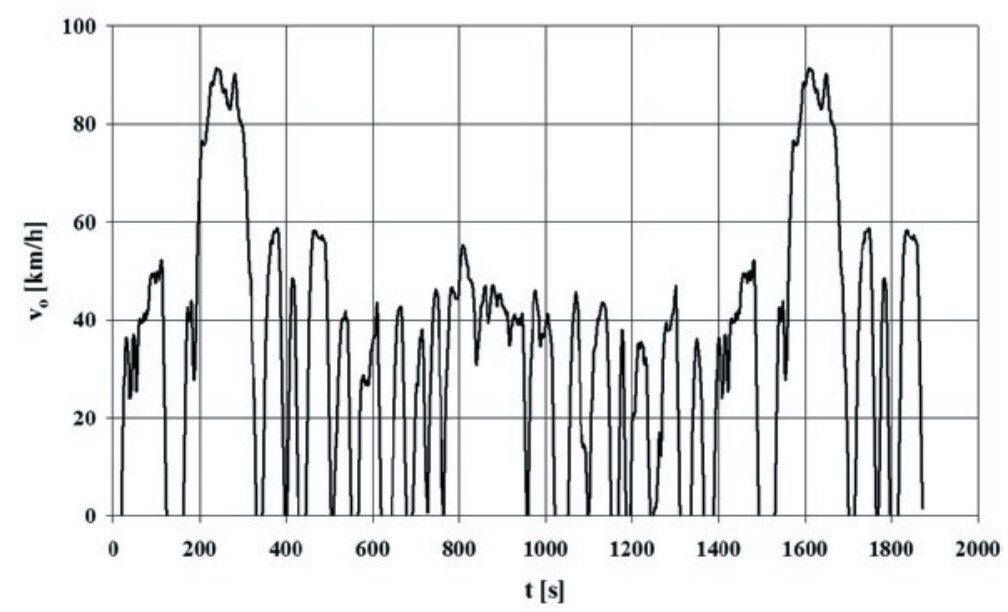

Fig. 1. Process of velocity $-v_{o}$ in the FTP-75 cycle.

This cycle was developed as a precise simulation of on-road driving in the time domain by synthesizing selected trip segments representative of the tested velocity process. Segments of the velocity process representative of the tested velocity process are most commonly selected using cluster analysis [17, 20]. The designers of this cycle adopted the zero-dimensional parameters of the velocity process as comparison criteria, and next concatenated the selected representative trip segments using the Monte Carlo method $[6,14]$ to create the cycle.

\section{Methodology of constructing driving cycles in ac- cordance with the criterion of similarity of frequency characteristics}

The method of generating pseudo-random realizations of the stochastic process modelling driving cycles in compliance with the criterion of similarity of frequency parameters uses amplitude-frequency characteristics of the velocity process of the reference cycle. The reference cycle based on FTP-75 is defined as a vector:

$$
\mathbf{v}_{\mathbf{o}}=\left[v_{o(i)}\right]^{T}
$$

where: $i=1, \ldots, L$, with $L=2^{K}$, and $K \in\{N\}$, i.e. $\mathrm{K}$ is a natural number.

The dimension of vector $\mathbf{v}_{\mathbf{0}}$ must be greater than the number of points of the discretized process of the FTP-75 cycle. In order to use a discrete algorithm for the Fourier transform, the discrete process of the reference cycle is padded with zeros up to the number of vector elements L.

The maximum and minimum values of the elements of vector $\mathbf{v}_{\mathbf{0}}$ are:

$$
\begin{aligned}
& v_{o \max }=\operatorname{Max}\left[\mathbf{v}_{\mathbf{o}}\right] \\
& v_{o \text { min }}=\operatorname{Min}\left[\mathbf{v}_{\mathbf{o}}\right]
\end{aligned}
$$

where: Max and Min are the operators of the largest and smallest values.

The distance between the elements of vector $\mathbf{v}_{\mathbf{0}}$ is:

$$
R\left[\mathbf{v}_{\mathbf{o}}\right]=\operatorname{Max}\left[\mathbf{v}_{\mathbf{o}}\right]-\operatorname{Min}\left[\mathbf{v}_{\mathbf{o}}\right]=R_{v_{o}}
$$

The Fourier transform image of vector $\mathbf{v}_{\mathbf{0}}$ is a vector whose elements are complex numbers:

$$
\mathbf{V}_{o}=F F T\left[\mathbf{v}_{o}\right]
$$

Each element of vector $\mathbf{V}_{\mathbf{0}}$ can be represented in the form of components: the real part $\mathbf{V}_{\mathbf{0}} \mathbf{R e}$ and the imaginary part $\mathbf{V}_{\mathbf{0} \text { Im }}$ or modulus $\mathbf{V}_{\mathbf{o}}$ Abs and argument $\mathbf{V}_{\mathbf{0} \text { Arg: }}$ :

$$
\mathbf{V}_{o}=\left[V_{o \operatorname{Re}(i)}+j \cdot V_{o \operatorname{Im}(i)}\right]^{T}=\left[V_{o A b s(i)} \cdot e^{j \cdot V_{o \operatorname{Arg}(i)}}\right]^{T}
$$

where $\mathrm{j}$ is an imaginary unit.

When driving cycles are modelled in accordance with the criterion of similarity to the amplitude-frequency parameters of the velocity process of the reference cycle, modulus values are assumed to be identical and a vector of pseudorandom numbers of arguments is generated. Vector of complex numbers $\mathrm{Y}$ is represented as:

$$
\mathbf{Y}=\left[Y_{\operatorname{Re}(i)}+j \cdot Y_{\operatorname{Im}(i)}\right]^{T}=\left[Y_{A b s(i)} \cdot e^{j \cdot Y_{\operatorname{Arg}(i)}}\right]^{T}
$$

For the inverse discrete Fourier transform of vector $\mathbf{Y}$ to be a vector of real numbers, the following conditions must be met, [18]:

$$
\begin{gathered}
Y_{\operatorname{Re}(1)}=0, Y_{\operatorname{Im}(1)}=0 \\
Y_{\operatorname{Re}\left(2^{K-1}\right)}=0, Y_{\operatorname{Im}\left(2^{K-1}\right)}=0
\end{gathered}
$$




$$
\begin{gathered}
Y_{\operatorname{Re}(k)}=Y_{\operatorname{Re}(i)} \\
Y_{\operatorname{Im}(k)}=-Y_{\operatorname{Im}(i)}
\end{gathered}
$$

where: $k=2^{K}-i$, and $i=2, \ldots, 2^{K-1}-1$.

Elements of vector Y are modelled as pseudorandom numbers:

$$
\begin{aligned}
& Y_{\operatorname{Re}(i)}=V_{o A b s(i)} \cdot \cos R n d_{(i)} \\
& Y_{\operatorname{Im}(i)}=V_{o A b s(i)} \cdot \sin R n d_{(i)}
\end{aligned}
$$

where: Rnd - vector of uniformly distributed pseudorandom numbers, where $\operatorname{Rnd}_{(i)} \in\langle-\pi ; \pi\rangle$.

The inverse discrete Fourier transform of vector $\mathbf{Y}$ is a vector of real numbers:

$$
\begin{gathered}
\mathbf{y}=F F T^{-1}[\mathbf{Y}]^{T}=\left[y_{\operatorname{Re}(i)}+y_{\operatorname{Im}(i)}\right]^{T} \\
y_{\operatorname{Im}(i)} \equiv 0
\end{gathered}
$$

where: $i=1, \ldots, L$

The maximum and minimum values and the distance between elements of vector $\mathbf{y}_{\mathbf{R e}}$ are:

$$
\begin{gathered}
y_{\mathrm{Remax}}=\operatorname{Max}\left[\mathbf{y}_{\mathbf{R e}}\right] \\
y_{\operatorname{Remin}}=\operatorname{Min}\left[\mathbf{y}_{\mathbf{R e}}\right] \\
R\left[\mathbf{y}_{\mathbf{R e}}\right]=\operatorname{Max}\left[\mathbf{y}_{\mathbf{R e}}\right]-\operatorname{Min}\left[\mathbf{y}_{\mathbf{R e}}\right]=R_{y_{\mathrm{Re}}}
\end{gathered}
$$

The elements of the vector representing the realizations of the stochastic process modelling the driving cycle are scaled so that the maximum and minimum values of the realizations are equal to the maximum and minimum values of the elements of the reference cycle vector.

$$
v_{(i)}=v_{o \text { min }}+\frac{R_{v_{o}}}{R_{y_{\operatorname{Re}}}} \cdot\left(y_{\operatorname{Re}(i)}-y_{\operatorname{Re} \min }\right)
$$

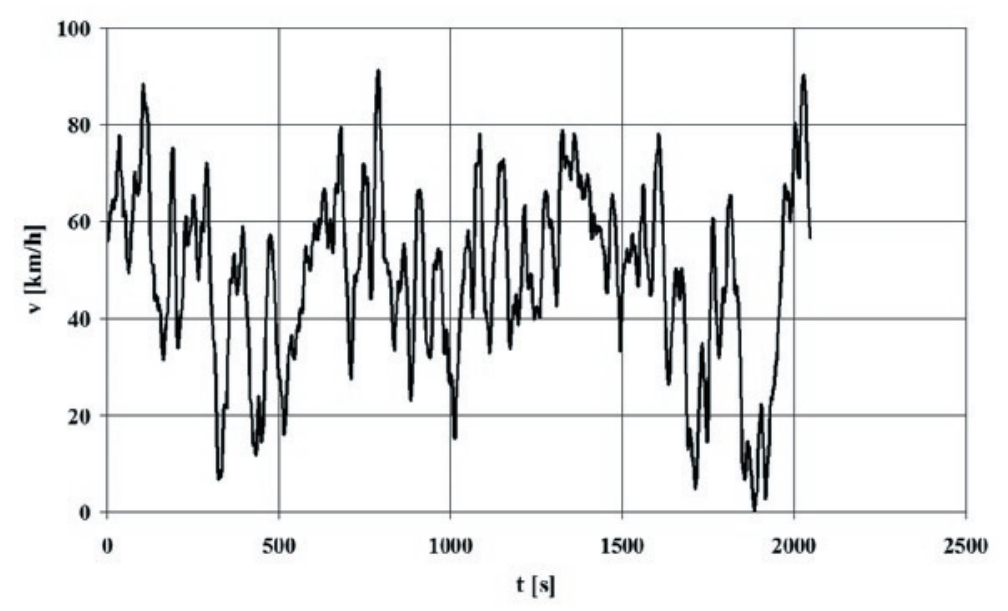

Fig. 2. An example of a velocity realization $-v$ of a vehicle operated over the reference driving cycle.

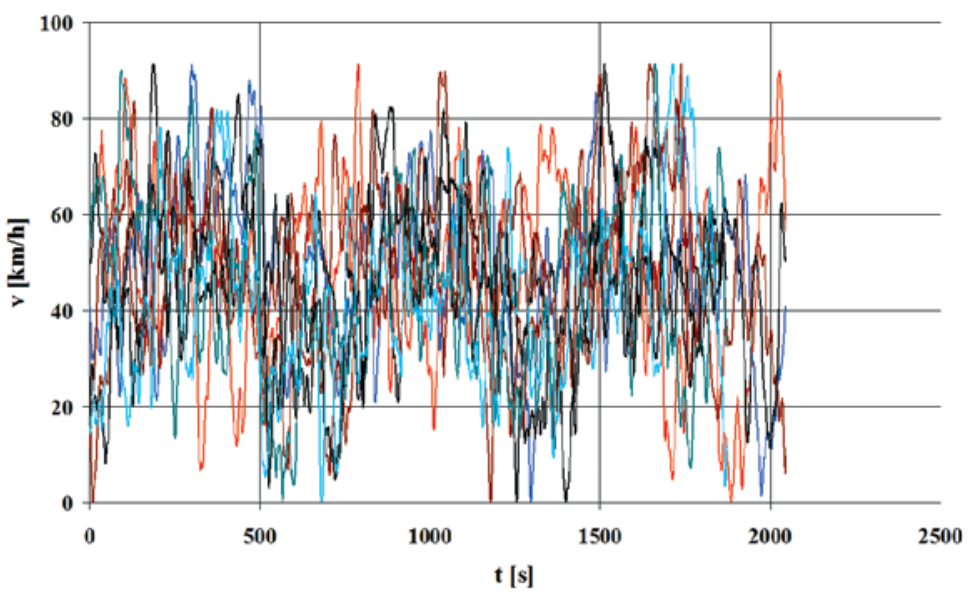

Fig. 3. A set of eight velocity realizations -v over the reference cycle

where: $\quad i=1, \ldots, L$.

Figure 2 shows an example of a velocity realization of a vehicle driven over the reference cycle. Figure 3 shows a set of eight realizations of the reference driving cycle.

To determine power spectral density of the velocity processes of the reference cycle and its realizations, Fast Fourier Transform was used. The linear trend was removed from the signal. To improve the compatibility of the power spectral density estimate, processing was done using a Hamming time window [10] and frequency smoothing of the rough estimate of power spectral density [18, 21]. Figure 4 shows the power spectral density of the velocity processes in the domain of dimensionless frequency relative to the Nyquist frequency [15], which is the maximum frequency of the spectral components of the signal being sampled - in accordance with the Kotelnikov-Shannon sampling theorem $[11,19]$ :

$$
f_{r}=\frac{f}{2 \cdot f_{N}}
$$

where: $f$ - frequency of the signal component,

$\mathrm{f}_{\mathrm{N}}-$ Nyquist frequency:

$$
f_{N}=\frac{1}{2 \cdot T_{S}}
$$

As can be seen, there is a considerable goodness of fit between the amplitude-frequency characteristics of the reference cycle and its realizations.

Of course, the fact that there is a close match between the criterion parameters of the reference cycle and its realizations does not mean that there is a match between other characteristics. Figure 5 shows a comparison of average and median of velocity between the reference cycle and its realizations.

Figure 6 shows a comparison of standard deviation and quartile deviation of velocity in the reference cycle and its realizations.

Figure 7 shows the coefficient of variation of velocity and the coefficient of quartile variation of velocity for the reference cycle and its realizations. The coefficient of quartile variation is defined as:

$$
W Q=\frac{D Q}{|M|}
$$




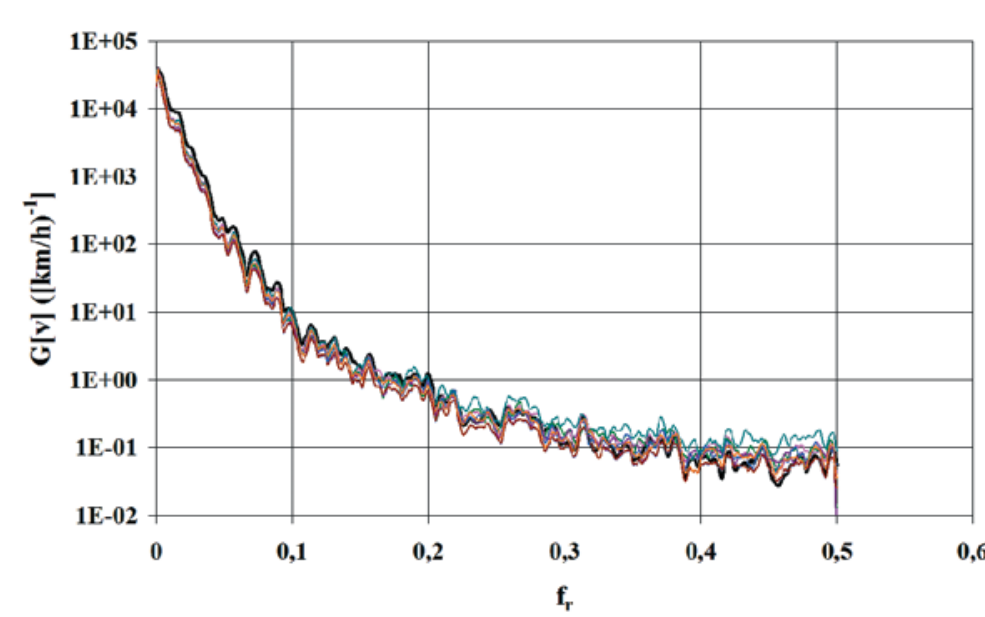

Fig. 4. Power spectral density - G of the reference cycle velocity process (thicker black line) and the velocity processes of the individual realizations of this cycle pared (eight), can be interpreted as a measure of low non-repeatability $[5,8]$.

We also evaluated the properties of the realizations of the reference cycle and the properties of the FTP-75 cycle in the process value domain.

Figure 9 compares the discrete probability density of velocity in the FTP-75 cycle and in realization No. 1 of the cycle.

It is not surprising that the difference between the probability density of velocity in the FTP-75 cycle and in one of its realizations is prominent given that the cycle was synthesized on the basis of a frequency parameter and not a parameter in the process value domain.

Figure 10 shows the discrete probability densities of the individual realizations of the test cycle velocity schedule.

Despite the apparent differences in the probability density of velocity among the individual realizations of the test cycle, certain similarities between the evaluated characteristics can also be observed.

Figure 11 shows a set of parameters characterizing the prob-

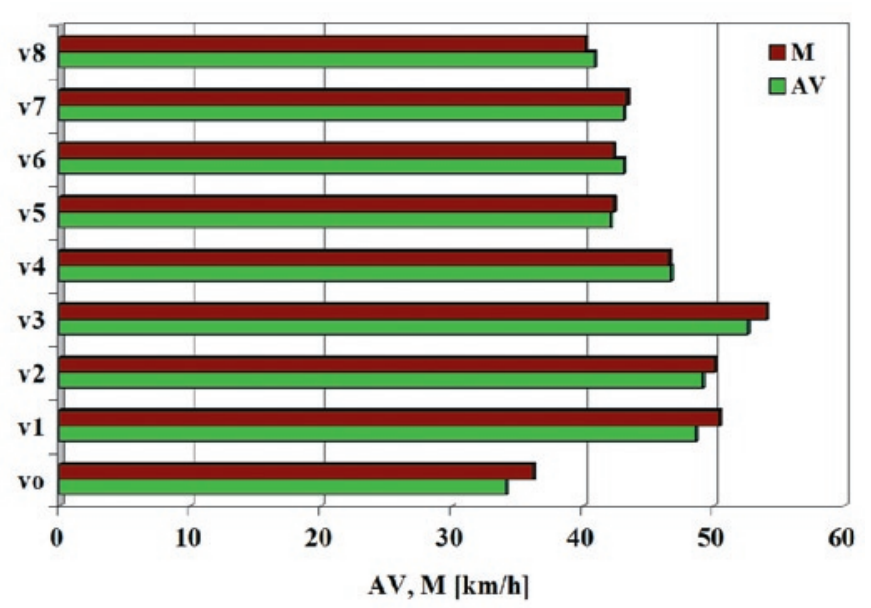

Fig. 5. Comparison of average velocity $-A V$ and median velocity $-M$ in the reference cycle and in its realizations

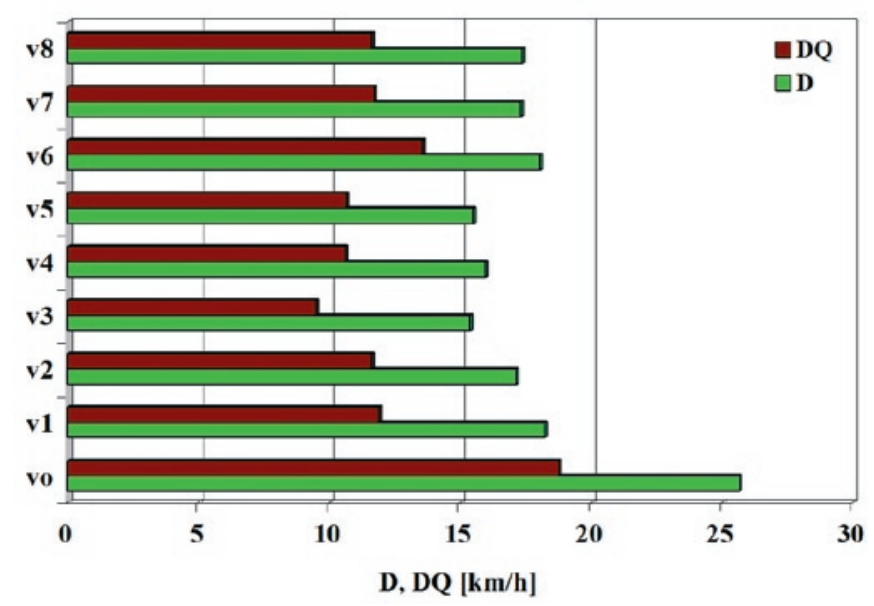

Fig. 6. Comparison of standard deviation $-D$ and quartile deviation $-D Q$ of velocity in the reference cycle and its realizations

where: $\mathrm{DQ}$ - quartile deviation,

$$
\mathrm{M}-\text { median. }
$$

Despite the differences in average velocity among the individual realizations of the cycle (Fig. 8), the coefficient of variation of average velocity was 0.09 , which, given the small number of values com-

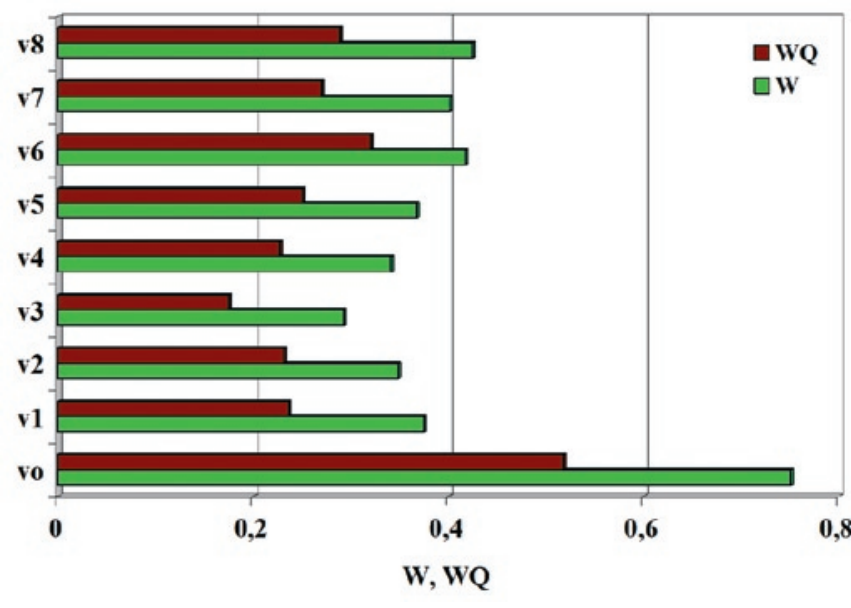

Fig. 7. Coefficient of variation $-W$ and coefficient of quartile variation $-W Q$ of velocity in the reference cycle and in its realizations

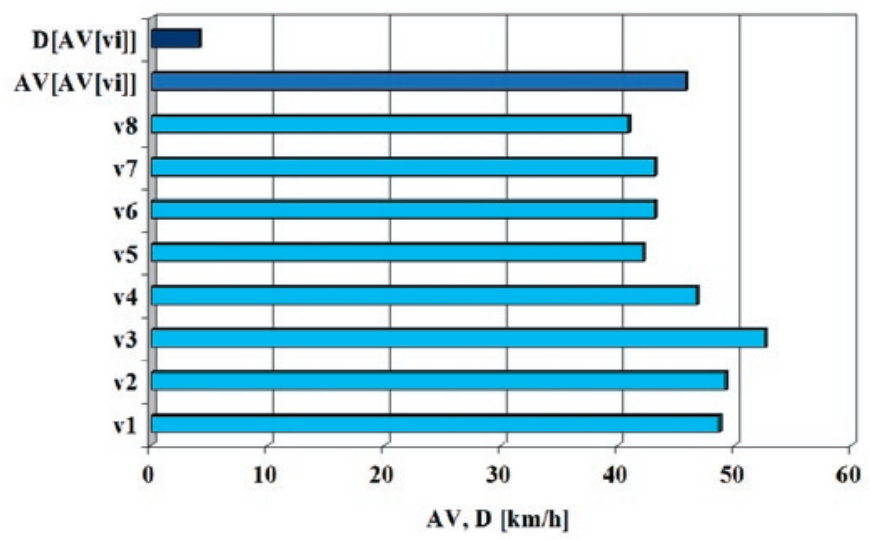

Fig. 8. Average velocity $-A V$ in the particular realizations of the cycle and the mean value $-A V\left[A V\left[v_{i}\right]\right]$ and standard deviation $-D\left[A V\left[v_{i}\right]\right]$ of average velocity of the individual realizations of the test

ability density of the individual realizations of the test cycle: skewness and kurtosis.

Both skewness and kurtosis vary for the different realizations, however, the coefficients are not too high. The investigated processes have both platykurtic and leptokurtic distributions. And the distributions show both a left-handed and a right-handed asymmetry. 


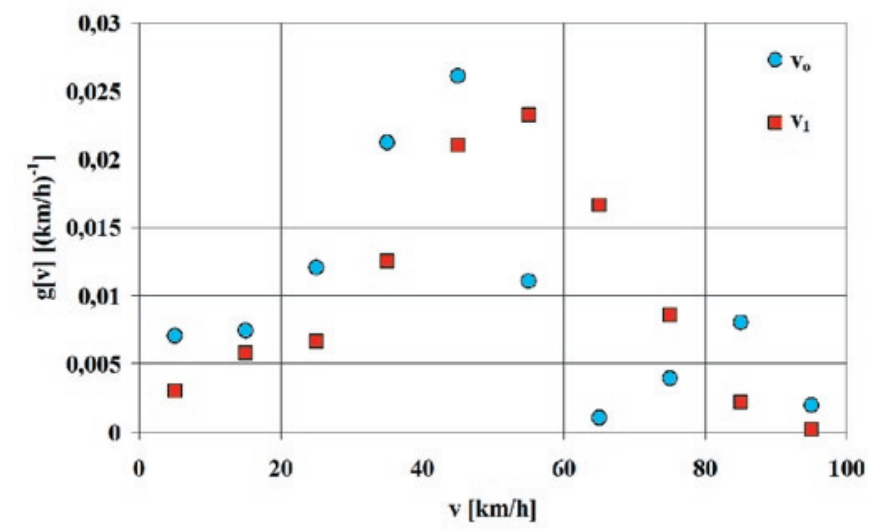

Fig. 9. Probability density $-g$ of velocity in the FTP-75 cycle $\left(v_{0}\right)$ and in realization No. 1 of the cycle $\left(v_{1}\right)$ : a discrete form of the probability density function and normal distributions approximating discrete sets

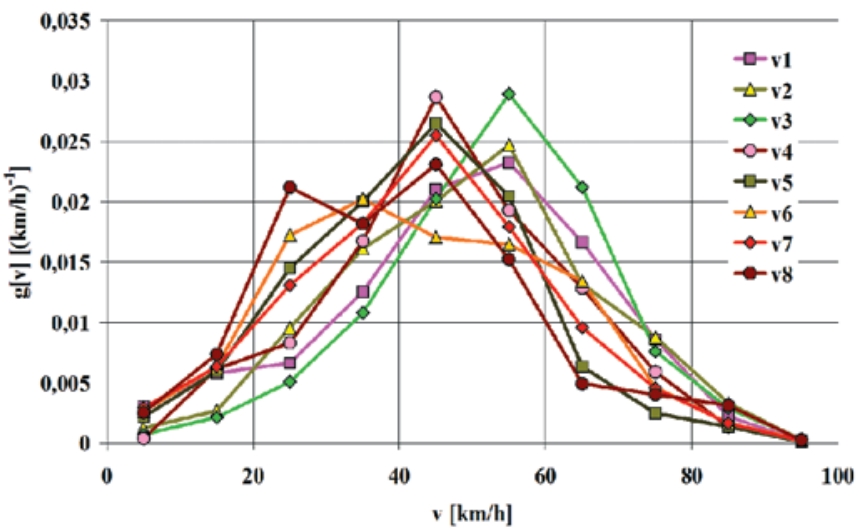

Fig. 10. Discrete probability density $-g$ of each realization of the test cycle velocity schedule.

\section{Conclusions}

In this article, we proposed a method for synthesizing driving cycles treated as sets of realizations of a stochastic velocity process. This approach, which uses the criterion of similarity of on-road and test

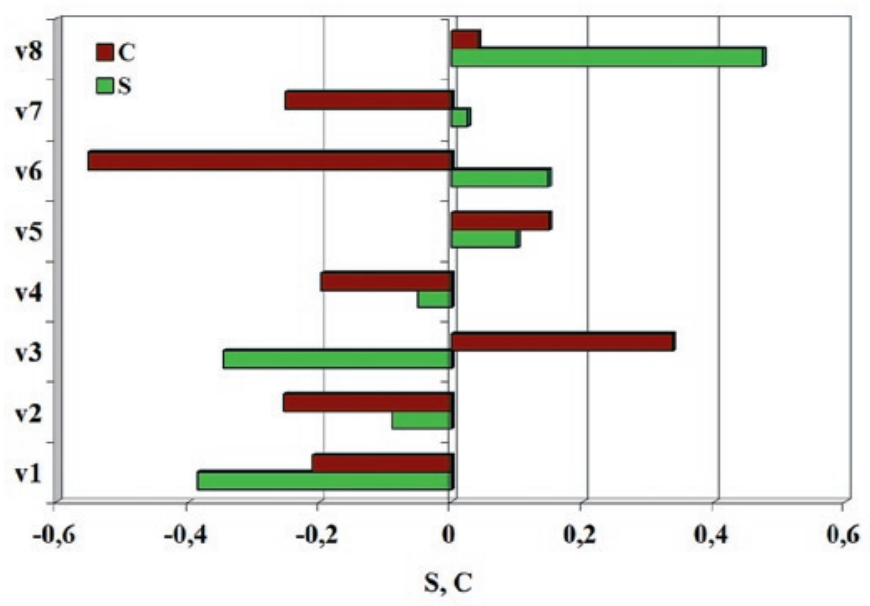

Fig. 11. Skewness $-S$ and kurtosis $-C$ of the probability density of the individual realizations of the test cycle.

amplitude-frequency driving characteristics, is an original way of investigating the functional properties of vehicles. Because a driving cycle is treated here as a set of realizations of a random process, the method allows not only to determine the values of the zero-dimensional characteristics being assessed (which define the functional properties of a car), but also to evaluate the probabilistic properties of these parameters.

The example of synthesis of driving cycles, treated as sets of realizations of a stochastic process of car velocity, demonstrates the effectiveness of the proposed method. The velocity processes determined in the experiments have similar probabilistic characteristics, which is usually the case in the practice of testing realizations of stochastic processes [16]. In the future, the method is planned to be further investigated in chassis dynamometer tests performed using the driving cycle realizations obtained in this study.

\section{References}

1 Andersson J et al. - On-road and chassis dynamometer evaluations of emissions from two Euro 6 diesel vehicles. SAE 2014-01-2826.

2. André M. - The ARTEMIS European driving cycles for measuring car pollutant emissions. Science of the Total Environment 2004; 334-335: 73-84, http://dx.doi.org/10.1016/j.scitotenv.2004.04.070.

3. BUWAL, INFRAS AG. Luftschadstoffemissionen des Strassenverkehrs 1950-2010. BUWAL-Bericht Nr. $255,1995$.

4. Chłopek Z. - Modelowanie procesów emisji spalin w warunkach eksploatacji trakcyjnej silników spalinowych. Prace Naukowe. Seria Mechanika" z. 173. Warszawa: Oficyna Wydawnicza Politechniki Warszawskiej, 1999.

5. Chłopek Z. - Testing of non-repeatability of pollution emission from motor-car engines. Silniki Spalinowe - Combustion Engines 2004; 1: 40-51.

6. Chłopek Z. - The cognitive interpretation of the Monte Carlo method for the technical applications. Eksploatacja i Niezawodnosc Maintenance and Reliability 2009; 3: 38-46.

7. Favre C, Bosteels D, May J. - Exhaust emissions from European market available passenger cars evaluated on various drive cycles. SAE 2013-24-0154

8. Fisz M. - Probability theory and mathematical statistics. New York: Wiley, 1963.

9. G. Souffran, L. Miegeville, and P. Guerin. - Simulation of real-world vehicle missions using a stochastic Markov model for optimal powertrain sizing. IEEE Transactions on Vehicular Technology 2012; 61(8): 3454-3465, http://dx.doi.org/10.1109/TVT.2012.2206618.

10. Hamming R W. - Numerical methods for scientists and engineers. New York: McGraw-Hill, 1962.

11. Kotelnikov V A. - On the transmission capacity of "ether" and wire in electrocommunications. (English translation). Moscow: Svyazzi RKKA, 1933. Reprint in Modern Sampling Theory: Mathematics and Applications. Boston: Birkhauser, 2000.

12. Lijuan W et al. - Modeling heavy/medium-duty fuel consumption based on drive cycle properties. SAE 2015-01-2812.

13. May J, Bosteels D, Favre C. - A comparison of light-duty vehicle emissions over different test cycles and in real driving conditions. SAE 2014-01-1581. 
14. Metropolis N, Ulam S. - The Monte Carlo method. Journal of the American Statistical Association 1949; 44(247): 335-341, http://dx.doi. org/10.1080/01621459.1949.10483310.

15. Nyquist H. - Thermal agitation of electric charge in conductors. Physical Revue 1928; 32: 110-113, http://dx.doi.org/10.1103/ PhysRev.32.110.

16. Papoulis A, Pillai S U. - Probability, random variables and stochastic processes. 4th edition. McGraw Hill, 2002.

17. Qin Shi et. al. - The study of a new method of driving cycles construction. Procedia Engineering Volume 2011; 16: 79-87, http://dx.doi. org/10.1016/j.proeng.2011.08.1055.

18. Ralston A, Wilf H S. - Mathematical methods for digital computers. New York: John Wiley, 1960.

19. Shannon C E. - A mathematical theory of communication. Bell System Technical Journal 1948; 27: 379-423, 623-656, http://dx.doi. org/10.1002/j.1538-7305.1948.tb01338.x.

20. Tryon R C. - Cluster analysis: Correlation profile and orthometric (factor) analysis for the isolation of unities in mind and personality. Ann Arbor: Edwards Brothers, 1939.

21. Tukey J W. - An introduction to the calculations of numerical spectrum analysis. Spectral Analysis of Time Series 1967: 25-46.

22. Tutuianu M et al. - Development of a world-wide worldwide harmonized light duty driving test cycle (WLTC). Technical Report UN/ECE/ WP.29/GRPE/WLTP-IG DHC subgroup. December 2013.

23. Worldwide emission standards. Passenger cars and light duty vehicles. Delphi. Innovation for the real world. 2016/2017.

\section{Zdzisław CHŁOPEK}

Automotive Industry Institute

55 Jagiellonska Street, 01-301 Warsaw, Poland

E-mail: Zdzislaw.Chlopek@pimot.eu 